\title{
Why are Hydrogen Bonds Directional?
}

\author{
ABHISHEK SHAHI and ELANGANNAN ARUNAN* \\ Department of Inorganic and Physical Chemistry, Indian Institute of Science, Bangalore, \\ Karnataka 560 012, India \\ e-mail: arunan@ipc.iisc.ernet.in
}

MS received 16 June 2016; revised 6 August 2016; accepted 11 August 2016

\begin{abstract}
The recent IUPAC recommendation on the definition of hydrogen bonding points out that directionality is a defining characteristic of a hydrogen bond and the angle $\angle \mathrm{X}-\mathrm{H}-\mathrm{Y}$ is generally linear or $180^{\circ}$. It also suggests that the $\mathrm{X}-\mathrm{H} \cdots \mathrm{Y}$ angle be greater than $110^{\circ}$ for an interaction to be characterized as a hydrogen bond but does not provide any rationale for the same. This article reports a rationale for limiting the angle, based on the electron density topology using the quantum theory of atoms in molecules. Electron density topology for common hydrogen bond donors $\mathrm{HF}, \mathrm{HCl}, \mathrm{HBr}, \mathrm{HNC}, \mathrm{HCN}$ and $\mathrm{HCCH}$ are reported in this work. These calculations lead to an interesting observation that the atomic basins of $\mathrm{H}$ atom in all these donor molecules are limited justifying the restriction of hydrogen bond angle. Moreover, similar analysis on some hydrogen bonded complexes confirms that beyond this angle the acceptor atom Y starts interacting with the atomic basin on X. However, conclusions based on bond lengths and angles have to be treated with care and as the IUPAC recommendation points out that independent 'evidence for bond formation' in every case is important.
\end{abstract}

Keywords. Hydrogen Bonding; non-covalent interactions; hydrogen bond angle; atoms in molecules theory; electron density topology.

\section{Introduction}

It is 100 years since Lewis came up with the "electron pair bond' ${ }^{1}$ which was called the 'covalent bond' by Langmuir, ${ }^{2}$ the name that survived. The suggestion of electron pair bond is revolutionary as Lewis contended that two electrons having the same charge come together to form the chemical bond. Though electron spin was yet to be discovered, Lewis knew the stable electronic configurations in atoms and realized that two atoms sharing an electron each could give both of them stable electronic configurations as found in rare gases. An ionic or electrostatic bond ${ }^{3}$ between a positively charged cation and a negatively charged anion was already familiar to chemists as it involves the well-known Coulombic or electrostatic attraction between them. Lewis succeeded in explaining the 'chemical bonds' that held the neutral molecules together. The covalent bonding has dominated chemistry so much over the last century and most chemists appear to think of "chemical bond' as 'only covalent bond'. It is indeed ironic as no one could deny that $\mathrm{KCl}$ molecule in the gas phase, having an ionic bond, is a chemical.

Another revolutionary suggestion came from Latimer and Rodebush within a few years, in 1920, from the

*For correspondence

Celebrating 100 years of Lewis Chemical Bond same Chemistry Department in Berkeley as Lewis. ${ }^{4}$ They suggested that an $\mathrm{H}$ atom in $\mathrm{H}_{2} \mathrm{O}$ could be attracted to an $\mathrm{O}$ atom from a neighboring $\mathrm{H}_{2} \mathrm{O}$ molecule and it constituted a 'weak bond' i.e., the hydrogen bond. The $\mathrm{H}$ atom with only one electron was to be monovalent and could form only one covalent bond. Hence, the suggestion of the hydrogen bond violated the 'octet rule' of Lewis, another name coined by Langmuir. Due to this reason, the hydrogen bond was considered to be purely electrostatic by Pauling and this view remained dominant for long and is persisting among many even today. This is an incomplete, if not incorrect, picture and the reader is referred to a recent article in Resonance, Journal of Education. ${ }^{5}$

The IUPAC came up with a modern definition of the hydrogen bond, X-H . . Y-Z, in 2011. ${ }^{6}$ It was accompanied by a comprehensive technical report providing historical developments on the hydrogen bond and also the rationale for the new definition. ${ }^{7}$ It states that no single physical force can be attributed to 'hydrogen bonding' and directionality is a defining characteristic. While, it has been widely accepted, it has not stopped the debate about the nature of physical forces involved in hydrogen bonding. How does it become directional? One thing that is common in all this debate is the assumption that the intermolecular interaction can be meaningfully partitioned into various components such as electrostatics, induction, covalency, and exchange-correlation. 
A recent manuscript ${ }^{8}$ titled 'Anti-electrostatic hydrogen bond' discusses a hydrogen bond formed between two anions $\mathrm{F}^{-}$and $\mathrm{HCO}_{3}{ }^{-}$. That two anions can indeed form a hydrogen bond is not a new observation and it has been reported earlier as a matter of fact. More interestingly, the title of that manuscript is 'Electrostatics at the origin of the stability of phosphate-phosphate complexes locked by hydrogen bonds '. ${ }^{9}$ Another manuscript discusses positively charged $\mathrm{P}$ as hydrogen bond acceptor. ${ }^{10}$ None of these results are surprising when one realizes that the charge distribution is not spherical in most molecules or even atoms. The $\mathrm{HCO}_{3}{ }^{-}$anion has a dipole moment with $\mathrm{H}$ being the positive end and it is a hydrogen bond donor, $\mathrm{X}-\mathrm{H}$ to the anion $\mathrm{F}^{-}$. The 'positive' $\mathrm{P}$ in the $\mathrm{PH}_{3}$ molecule has electron rich regions due to its lone pair of electrons and it is a hydrogen bond acceptor, Y. There is nothing 'anti-electrostatic' about these hydrogen bonds formed by ions/atoms having similar charges.

The proponents of 'covalency' in hydrogen bonding can find orbitals in the right position for an overlap leading to stability. However, covalency in hydrogen bonding seems more contentious. Some are of the view that if covalency cannot be established, it should not be called hydrogen 'bond'! It is clearly the result of the dominant view of chemical bond as covalent and is rather surprising as ionic bonds are taught along with covalent bonds from high school days. We recently observed that the total bond order, including covalency and ionicity, is conserved when an X-H forms an X-H. . Y hydrogen bond. ${ }^{11}$ An interesting observation from this study is that the H...Y bond is dominantly, but not entirely, ionic. A recent atomic force microscopy study attracted widespread attention with an image showing some electron density between $\mathrm{H}$ and $\mathrm{O} / \mathrm{N}$ atoms in wellestablished $\mathrm{O}-\mathrm{H} \cdots \mathrm{O}$ and $\mathrm{O}-\mathrm{H} \cdots \mathrm{N}$ hydrogen bonds in 8 -hydroxyquinoline. ${ }^{12}$ No one would have questioned their characterization as hydrogen bonds prior to the publication of this image. However, the interpretation of the AFM image as due to a 'hydrogen bond' has been questioned in later studies and the debate continues. ${ }^{13,14}$ Buckingham et al. ${ }^{15}$ had perhaps underestimated the zeal of chemists when they wrote: 'the debate about the origin of hydrogen bonding is relegated to history' following the universal acceptance of quantum-mechanical nature of all interactions. Even if the interpretation of AFM image is questionable, there ought to be some, however small, electron density between $\mathrm{H}$ and $\mathrm{Y}$ atoms in all hydrogen bonds.

Comparison of the structures of simple dimers of LiF and HF would be an interesting exercise. ${ }^{5,16}$ The former has two minima, with the dipoles oriented either parallel or anti-parallel, as classical electrodynamics would predict. The latter has neither of this geometry and the two HF molecules are located at a tilted angle. Those who see covalency in hydrogen bond are happy to see the lone pair in the hydrogen bond acceptor $\mathrm{F}$ atom along the direction in which the $\mathrm{H}$ from the donor approaches. Those convinced of the importance of electrostatic interactions point out that addition of the quadrupole moment of HF leads one to the observed geometry. ${ }^{17}$ In most of these cases, it is also possible to find a sigma hole behind $\mathrm{H}$ atom which is filled by the excess electron density of the acceptor. Sigma hole was introduced to explain the halogen bond analogous to hydrogen bond as electronegative halogen atoms coming towards an electron donor was causing some confusion earlier. ${ }^{18,19}$

While the experts continue to debate about the physical forces involved in hydrogen bond, experimental chemists, in particular those working in the condensed phase, rely on $\mathrm{H} \cdots \mathrm{Y}$ distance and $\mathrm{X}-\mathrm{H} \cdots \mathrm{Y}$ bond angle to conclude about the presence of a hydrogen bond. The distance between $\mathrm{H}$ and $\mathrm{Y}$ should be less than the sum of their van der Waals radii and the X-H... Y angle should be above $110^{\circ}$. The distance criterion is based on the way van der Waals radius was defined by Pauling after looking at the closest distance between two atoms that are 'not-bonded' in a crystal. ${ }^{3}$ Hence, if two atoms have a distance shorter than this, they could be 'bonded'. We are not aware of any specific logic in deriving the 'lowest hydrogen bond angle', though it has been suggested by several authors., ${ }^{720-22}$ It is likely that this was chosen to exclude an anti-parallel geometry in which the $\mathrm{X}-\mathrm{H} \cdots \mathrm{Y}$ angle could be $90^{\circ}$ and that would be evidence for electrostatic interactions between two dipoles.

Several authors have pointed out that the use of van der Waals radius to identify hydrogen bond could be misleading ${ }^{20,21}$ and the IUPAC report echoed the same view as well. ${ }^{7}$ We have earlier shown that 'hydrogen bond radii' for X-H donors and $\mathrm{Y}$ acceptors could be defined to interpret the $\mathrm{H}$. . Y distance. ${ }^{23-25}$ Our initial work followed the lead by Gadre and Bhadane, ${ }^{26}$ who used the minimum in molecular electrostatic potential of an acceptor to determine the acceptor radius. However, this approach does not give any direct determination of the 'hydrogen bond radii', which is possible with the electron density topology analysis, made popular as the Atoms in Molecules theory by Bader. ${ }^{27}$ Klein has in fact used the electron density topology to come to similar conclusions as ours. ${ }^{28,29}$ Several authors have highlighted the fact that atoms are not 'spherical', certainly not the way they are found in a molecule. ${ }^{30-32}$

Recently, we started investigating the angular dependence of the 'hydrogen bond radii' for various donors 
using the Atoms in Molecules (AIM) theoretical approach. When, we looked at the atomic basin in all the donors, it offered a theoretical justification for the lower limit for the hydrogen bond angle. These results are presented in this manuscript. It should be highlighted that, our work focuses on the $\mathrm{X}-\mathrm{H} \cdots \mathrm{Y}$ angle and why it is mostly linear. Another important parameter in the general hydrogen bond (X-H. . Y Y Z ) geometry is the angle $\mathrm{H} \cdots \mathrm{Y}-\mathrm{Z}$ and it is governed by how $\mathrm{Y}$ accepts the hydrogen bond. Legon and Millen came up with an empirical rule pointing out that the $\mathrm{H}$ approaches towards a lone pair in $\mathrm{Y}$ or a $\pi$ pair in $\mathrm{Y}-\mathrm{Z}$ and when both are available, the lone pair is preferred. ${ }^{33} \mathrm{We}$ have recently extended the Legon-Millen rule for $\mathrm{H} / \mathrm{Cl} / \mathrm{Li}$ bond with acceptors not limited to lone pair or $\pi$ electrons. ${ }^{11}$ The modified Legon-Millen rule was stated as: The equilibrium angular geometry of an X-bonded complex $A \cdots X-D$ can be predicted by assuming that the bond axis of the $X-D$ is collinear with the line connecting $A$ and $X$, with $A$ being an atom or a bond centre, electrons of which are the acceptors of $X$-bond from $X D$. In addition to lone pair and $\pi$ electrons, the acceptor region could be an unpaired electron as in $\mathrm{CH}_{3}$ radical, $\sigma$ electrons as in $\mathrm{H}_{2}$ and even a rare gas atom. ${ }^{11}$ We note that molecular electrostatic potentials have also been used extensively for predicting geometries ${ }^{34,35}$ and also for locating critical points. ${ }^{36,37}$

\section{Computational Methods}

The common hydrogen bond donors (H-D) selected for this study are $\mathrm{HF}, \mathrm{HCl}, \mathrm{HBr}, \mathrm{HNC}, \mathrm{HCN}$ and $\mathrm{HCCH}$. All molecules are optimized at MP2/6-311++G(d,p) level of theory using the Gaussian09 suite of programs. ${ }^{38}$ The normal mode frequency calculations have been done for all molecules at the same level of theory to ensure that the optimized structures are at minima. From the optimized geometry, wave function of the molecule is generated using Gaussian09 program for AIM analysis and AIM analysis is performed using the AIMAll program. ${ }^{39}$ The same procedure was followed for the hydrogen bonded complexes considered in the next section.

\section{Results and Discussion}

In Figure 1, different contours are plotted corresponding to $0.02,0.005,0.002$ and 0.001 a.u. electron density values for the HF molecule. Curved line passing through the bond critical point $(\mathrm{BCP})$ denotes the interatomic line in $2 \mathrm{D}$ contour plot. The green dot represents the $\mathrm{BCP}$. The essence of the AIM theory is the portioning

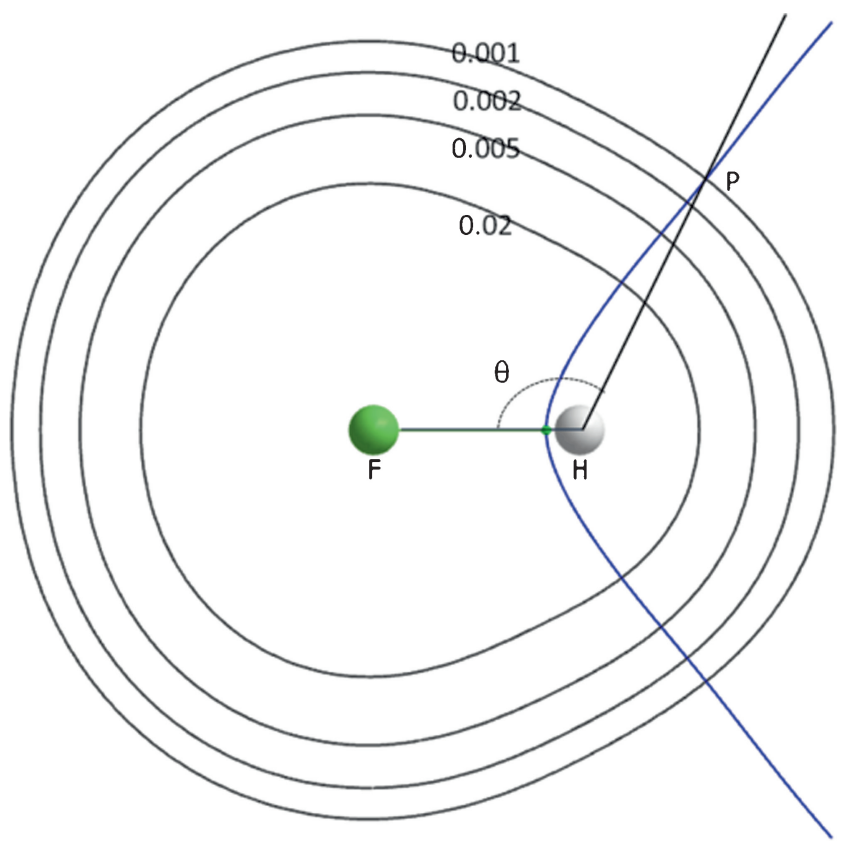

Figure 1. Atomic basins of $\mathrm{H}$ and $\mathrm{F}$ in the HF molecule are divided by the curved line going through the bond critical point. The angle $\theta$ is measured between the F-H bond axis and the solid line connecting to the point $\mathrm{P}$ from $\mathrm{H}$. At point $P$, the interatomic dividing line cuts the 0.001 a.u. contour, the minimum electron density expected at a $\mathrm{BCP}$ for hydrogen bond. This angle for HF is $115^{\circ}$.

of the properties for each atom from the overall molecular property. An interatomic surface or zero-flux surface defines a boundary of an atom from the rest of the molecule. The volume inside the boundary is called the basin of the particular atom and it consists of a large number of gradient paths terminating at the nucleus. Both 2D and 3D graph of inter-atomic surfaces, basins, gradient paths of electron density are presented in Figure 2 for HF molecule. The gradients propagating outwards of the molecules have been cut off at 0.001 a.u. Only if the acceptor atom approaches within this basin, it would be interacting with the $\mathrm{H}$ atom.

In order to put a limit on the hydrogen bond angle, the point at which the 0.001 au contour crosses the interatomic line, $\mathrm{P}$, was chosen. We chose this point for the following reasons. In general, the hydrogen bond is weaker as the hydrogen bond angle is reduced from $180^{\circ}$ and the electron density at the BCP will be lower. The generally accepted cut off in electron density is $0.001 \mathrm{au}$, which is also used to define van der Waals radii. ${ }^{28,29}$ The acceptor atom has to come at an angle larger than defined by this lower limit of the X-H..P angle, as defined in Figure 1, if it were to form a hydrogen bond.

Angles were determined for some linear hydrogen bond donors such as $\mathrm{HF}, \mathrm{HCl}, \mathrm{HBr}, \mathrm{HNC}, \mathrm{HCN}$ and 

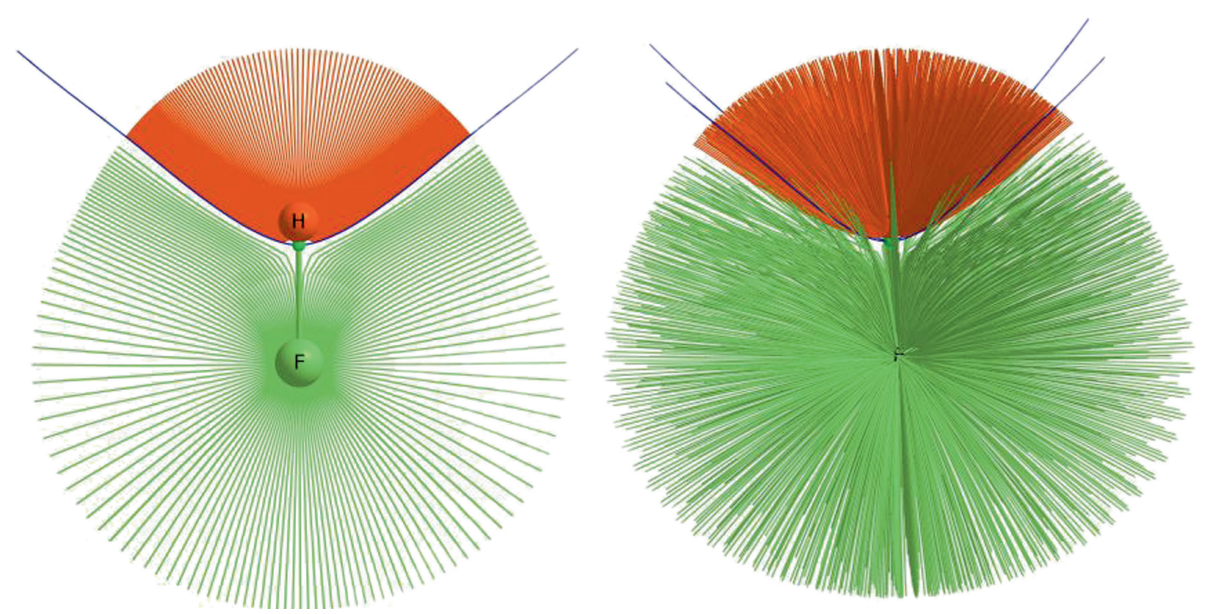

Figure 2. 2D (left) and 3D (right) atomic basins of HF molecule. The green area is for F-atom, red area is for $\mathrm{H}$-atom and blue solid lines are interatomic lines which define the boundary.

Table 1. Angles $\theta$ (see Figure 1) for the monomer H-X.

\begin{tabular}{lcccccc}
\hline & $H F$ & $H C l$ & $H B r$ & $H N C$ & $H C N$ & $H C C H$ \\
\hline Monomer & 115 & 100 & 97 & 106 & 95 & 97 \\
$X-H \cdots H_{3}$ & 120 & 105 & 105 & 114 & 102 & 108 \\
$X-H \cdots A r$ & 129 & 114 & 114 & 120 & 111 & 111 \\
\hline
\end{tabular}

HCCH (Table 1). Surprisingly, these varied from a much lower $95^{\circ}\left(\mathrm{HCN}\right.$, a weak donor) to $115^{\circ}$ (HF, a very strong donor). It may be noted that this angle reduces as the electronegativity of $\mathrm{X}$ reduces. Clearly, the atomic basin of $\mathrm{H}$ atom is restricted as the electronegativity difference between $\mathrm{X}$ and $\mathrm{H}$ increases. Just for comparison, similar calculations on $\mathrm{LiH}$ show this angle to be about $40^{\circ}$ ! When $\mathrm{H}$ is more electronegative, it occupies an atomic basin larger than the other atom. It has been known that hybridization of $\mathrm{X}(\mathrm{X}=\mathrm{C} / \mathrm{N})$ could change the shape and size of $\mathrm{H}$-atom in $\mathrm{H}$-X molecule. ${ }^{40,41} \mathrm{In}$ this work, we restricted to linear donors as non-linear donors such as $\mathrm{CH}_{2}=\mathrm{CH}_{2}$ and $\mathrm{R}-\mathrm{NH}_{2}$ would have asymmetric charge distribution requiring more than one angle depending on the direction of approach of Y.

How does the electron density topology affect the bonding between an X-H and A? Would the acceptor interact with $\mathrm{X}$ or $\mathrm{H}$ depending on the 'hydrogen bond angle' as defined in Figure 1? More importantly, would the acceptor alter the atomic basins in the donor? In order to investigate this, two model acceptors, $\mathrm{NH}_{3}$ as a strong hydrogen bond acceptor and Ar, as a weak hydrogen bond acceptor, were selected. Geometry of the twelve complexes between these two acceptors and the six donors ( $\mathrm{HF}, \mathrm{HCl}, \mathrm{HBr}, \mathrm{HNC}, \mathrm{HCN}$ and $\mathrm{HCCH}$ ) were optimized. These complexes, in their global minima, have 'hydrogen bond angles' closer to $180^{\circ}$ and have bond critical points connecting $\mathrm{H}$ to the acceptor atom, $\mathrm{N}$. We optimized the structure of these complexes using the relaxed scan method, inbuilt in Gaussian09 by varying the hydrogen bond angle with a step size of $3^{\circ}$ from $180^{\circ}$ to $90^{\circ}$. Obviously, the optimized structures at these lower angles would not be minima and our main objective was to look at the electron density topology at various angles. The AIM calculations have been performed for the structures at each step of the scan. Location of intermolecular 'BCP' and the bond path are monitored for each structure. The BCPs here give some indication about which atoms in the donor and acceptor are interacting and not necessarily denote a bond.

For $\mathrm{NH}_{3} \cdots \mathrm{H}-\mathrm{F}$, as the angle reduces from $120^{\circ}$ to $117^{\circ}$, the intermolecular bond path originating from $\mathrm{N}$ changes its direction towards fluorine from hydrogen (see the change in bond path in Figure 3). It appears that the lower limit is above $117^{\circ}$ for the "hydrogen bond angle" for $\mathrm{H}_{3} \mathrm{~N} \cdots \mathrm{HF}$. However, for the $\mathrm{H}_{3} \mathrm{~N} \cdots \mathrm{H}-\mathrm{Cl}$ and $\mathrm{H}_{3} \mathrm{~N} \cdots \mathrm{H}-\mathrm{Br}$, this change happens at $105^{\circ}$ though the cutoff angles expected from Table 1 are $100^{\circ}$ and $97^{\circ}$, respectively. For the six donors, the range of angles below which the intermolecular path connects $\mathrm{N}$ to $\mathrm{X}$ vary from $102^{\circ}-120^{\circ}$. For the Ar $\cdots \mathrm{H}-\mathrm{X}$ complexes, the hydrogen bond angles vary from $111^{\circ}-129^{\circ}$. Clearly, the acceptor can alter the range of angles in which hydrogen bonding can occur. In both cases, the lowest angle results when the donor is weak, $\mathrm{HCN} / \mathrm{HCCH}$ and the largest angle results for HF donor. In any case, it appears that $110^{\circ}$ is a reasonable cut off for hydrogen bond angle as the strong donors form more linear hydrogen bonds than weak donors.

Are there any real examples of hydrogen bonds down to $110^{\circ}$ ? The intermolecular hydrogen bonded complexes have hydrogen bond angles significantly larger than the generous cut off recommended by the IUAPC. ${ }^{6,7}$ For 

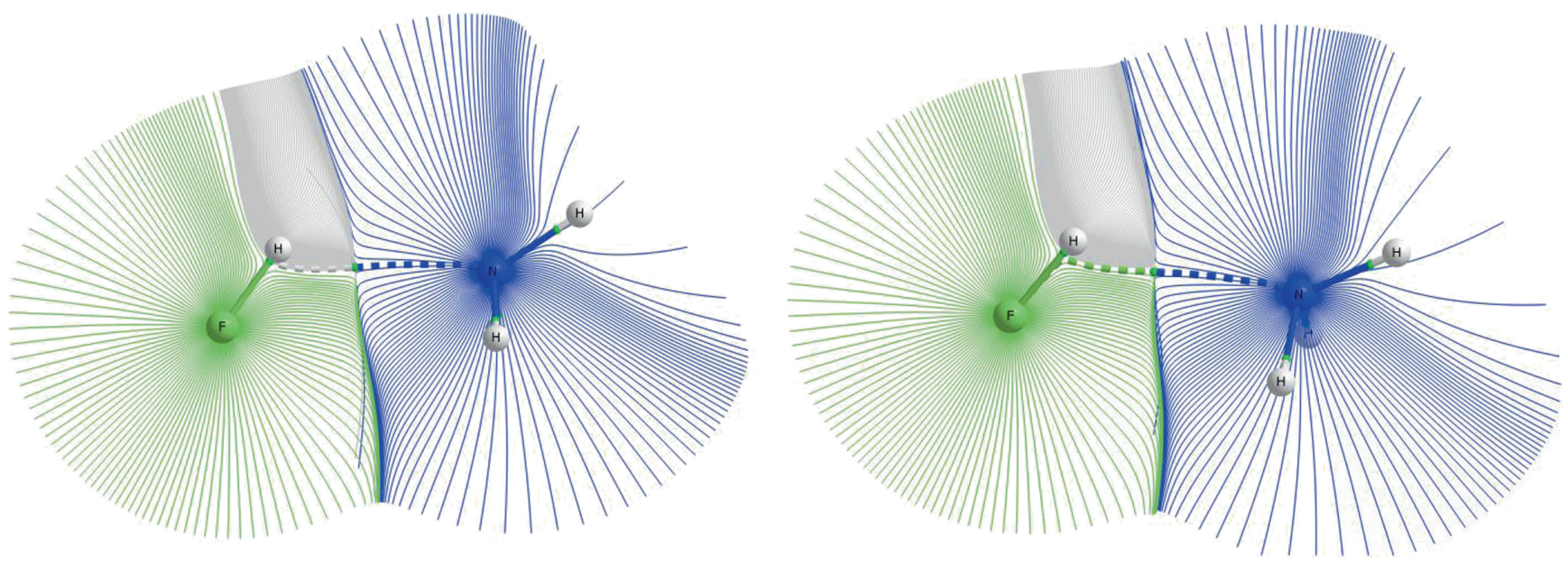

Figure 3. Example of $\mathrm{NH}_{3} \cdots \mathrm{HF}$ complex at two different angles, $120^{\circ}$ (left) and $117^{\circ}$ (right). In the left and right side figures $\mathrm{N}$ is 'bonded' with $\mathrm{H}$ and F-atom, respectively. Gradient path and interatomic lines are shown.

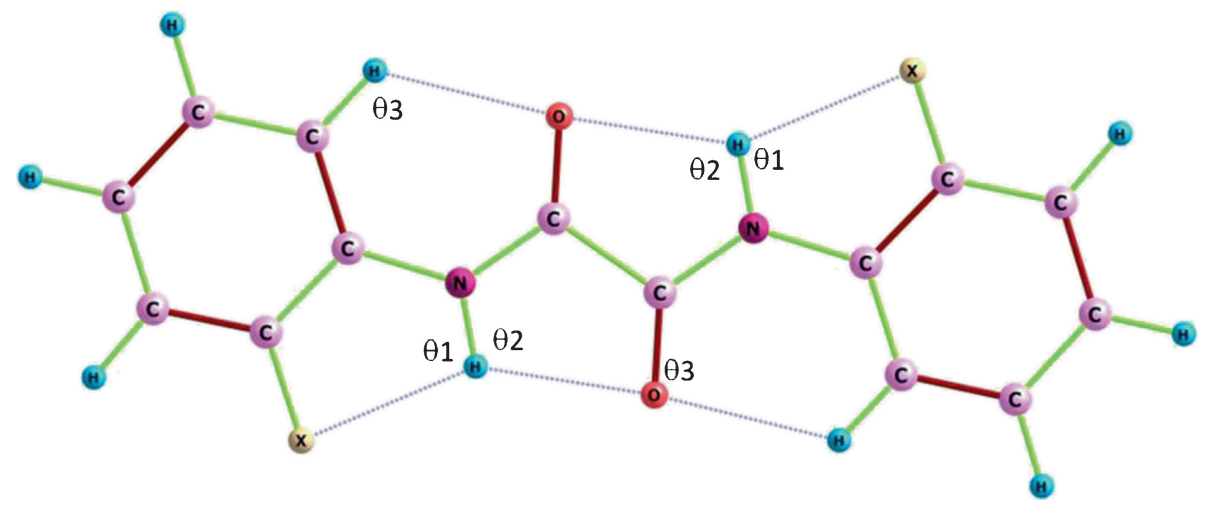

Figure 4. Molecular structure of diphenyloxamide derivatives. In the figure, $\mathrm{X}$ can be an atom $\mathrm{H}, \mathrm{F}, \mathrm{Cl}, \mathrm{Br}$, I or $\mathrm{CF}_{3}$ group.

example, $164^{\circ}$ was the lowest angle found in a comprehensive study on 100 complexes recently. ${ }^{11}$ Lower angles are likely to be observed for intramolecular hydrogen bonds or in complexes where multiple interactions are possible, such as 1,2-ethanediol (ethylene glycol ${ }^{42}$ or phenylacetylene- $\mathrm{H}_{2} \mathrm{O}$ complex. ${ }^{43}$ Somewhat coincidentally, a bond critical point was not observed for 'intramolecular hydrogen bond' in 1,2-ethanediol molecule, for which the $\mathrm{O}-\mathrm{H} \cdots \mathrm{O}$ angle turned out to be $108^{\circ} !^{43}$ However, the non-covalent index (NCI) plot, ${ }^{44}$ shows a dip confirming an attractive interaction corresponding to the intramolecular hydrogen bond in this molecule. ${ }^{45}$ The phenylacetylene- $\mathrm{H}_{2} \mathrm{O}$ complex has a nearly planar geometry in which both molecules simultaneously act as hydrogen bond donor and acceptor displaying $\mathrm{O}-\mathrm{H} \cdots \pi$ and $\mathrm{C}-\mathrm{H} \cdots \mathrm{O}$ hydrogen bonds. ${ }^{43}$ These have hydrogen bond angles of $155^{\circ}$ and $145^{\circ}$, respectively.

Another comprehensive study on diphenlyoxamide derivatives used NMR spectroscopy, AIM and NCI analyses on intramolecular hydrogen bonds. ${ }^{46}$ The structure of diphenyloxamide is shown in Figure 4 and it has the potential for three intramolecular hydrogen bonds. The three 'hydrogen bond angles' for the various derivatives are given in Table 2. It is interesting to note that in all the cases except one, the hydrogen bond angles are about $110^{\circ}$ or more. In the one case, where it is less, the acceptor is C-F bond and the donor is $\mathrm{N}-\mathrm{H}$ with an $\mathrm{N}-\mathrm{H} \cdots \mathrm{F}$ angle of $102.5^{\circ}$. The AIM analysis does not show a BCP corresponding to this interaction and again the NCI plot shows a dip corresponding to this interaction. NMR spectroscopic evidence was there for all intramolecular hydrogen bonds in these molecules. It is interesting to note that all these hydrogen bonds have an angle about $110^{\circ}$ or more. We have observed a similar trend in the hexafluoroisopropanol... water complex, for which the AIM analysis did not show a BCP but NCI plot showed an F... F interaction in the hexafluoroisopropanol. ${ }^{47}$

Before closing, it is worthwhile looking at the data from alkali halide dimers again. In the case of cyclic $\mathrm{NaF}$ dimer, ${ }^{16}$ the $\angle \mathrm{FNaF}$ and $\angle \mathrm{NaFNa}$ are about $85^{\circ}$ 
Table 2. Hydrogen bond angle for different diphenyloxamide derivatives $(\mathrm{X})$.

\begin{tabular}{lccc}
\hline $\mathrm{X}$ & $\mathrm{N}-\mathrm{H} \cdots \mathrm{X}(\theta 1)$ & $\mathrm{N}-\mathrm{H} \cdots \mathrm{O}(\theta 2)$ & $\mathrm{C}-\mathrm{H} \cdots \mathrm{O}(\theta 3)$ \\
\hline $\mathrm{H}$ & - & 111.2 & 120.2 \\
$\mathrm{~F}$ & 102.5 & 109.4 & 119.6 \\
$\mathrm{Cl}$ & 110.4 & 110.1 & 121.7 \\
$\mathrm{Br}$ & 113.5 & 109.9 & 122.1 \\
$\mathrm{I}$ & 116.7 & 110.3 & 122.8 \\
$\mathrm{CF} 3$ & $110.2(121.7)$ & 111.4 & 122.1 \\
\hline
\end{tabular}

and $95^{\circ}$, respectively. The AIM calculations identify bond critical points between all four atoms. This cyclic structure happens to be the global minimum for $\mathrm{NaF}$ dimer. This can be explained as the favorable interaction between two dipoles and there are bond critical points connecting the two $\mathrm{Na}$ atoms to both $\mathrm{F}$ atoms. It also has a local minimum, which is linear and similar to hydrogen bonded complexes.

\section{Conclusions}

For the hydrogen bond, a lower limit of $110^{\circ}$ has been recommended by IUPAC. In this work, electron density topology of typical donors has been analyzed to provide a rationale for this limit. The atomic basin corresponding to $\mathrm{H}$ atom in $\mathrm{XH}$ is limited to this angle. Not surprisingly, as the electronegativity difference between $\mathrm{X}$ and $\mathrm{H}$ is reduced, the $\mathrm{H}$ basin expands lowering this angle further, with $\mathrm{HBr}$ having the value of $97^{\circ}$. However, analysis of the electron density topology in typical complexes shows that even for $\mathrm{HBr}$, below $105^{\circ}, \mathrm{Br}$ starts interacting with the acceptor atom. In any case, as the IUPAC report pointed out, while these cutoffs can be used as a general measure, it is important to look for other experimental and theoretical evidence for hydrogen bond formation in specific cases. As the next step in our work, we are pursuing similar analysis on the non-linear hydrogen bond donors (like $\mathrm{H}_{2} \mathrm{O}$, $\mathrm{H}_{2} \mathrm{~S}$, etc.) considering the $3 \mathrm{D}$ atomic basins, which will give more insightful understanding of hydrogen bond directionality for non-linear donors.

\section{AUTHOR INFORMATION}

AS is presently at the Institute of Chemistry, The Hebrew University of Jerusalem, Israel. 91904.

\section{Acknowledgments}

Authors would like to thank the Super Computer Research Center and Inorganic and Physical Chemistry department at the Indian Institute of Science for providing good computational facilities and the Indo-French
Centre for Promotion of Advanced Scientific Research for financial support. AS would like to thank Council of Scientific and Industrial Research (CSIR) for the fellowship. AS also thanks Sharon Priya Gnanasekar and Kabir Kumbhar for their help in calculations.

\section{References}

1. Lewis G N 1916 J. Am. Chem. Soc. 38762

2. Langmuir I 1919 J. Am. Chem. Soc. 41868

3. Pauling L 1960 In The Nature of the Chemical Bond and the Structure of Molecules and Crystals: An Introduction to Modern Structural Chemistry (Ithaca New York: Cornell University Press)

4. Latimer W M and Rodebush W H $1920 \mathrm{~J}$. Am. Chem. Soc. 421419

5. Williams C, Zare R N and Arunan E 2014 Resonance 19 704

6. Arunan E, Desiraju G R, Klein R A, Sadlej J, Scheiner S, Alkorta I, Clary D C, Crabtree R H, Dannenberg J J, Hobza P, Kjaergaard H G, Legon A C, Mennucci B and Nesbitt D J 2011 Pure Appl. Chem. 831637

7. Arunan E, Desiraju G R, Klein R A, Sadlej, Scheiner S, Alkorta I, Clary D C, Crabtree R H, Dannenberg J J, Hobza P, Kjaergaard H G, Legon A C, Mennucci B and Nesbitt D J 2011 Pure Appl. Chem. 831619

8. Weinhold F and Klein R A 2014 Angew. Chem. Int. Ed. Engl. 12611396

9. Mata I, Alkorta I, Molins E and Espinosa E 2012 ChemPhysChem 131421

10. Hansen A S, Du L and Kjaergaard H G 2014 J. Phys. Chem. Lett. 54225

11. Shahi A and Arunan E 2014 Phys. Chem. Chem. Phys. 1622935

12. Zhang J, Chen P, Yuan B, Ji W, Cheng Z and Qiu X 2013 Science 342611

13. Hämäläinen $S \mathrm{~K}$, van der Heijden $\mathrm{N}$, van der Lit J, den Hartog S, Liljeroth P and Swart I 2014 Phys. Rev. Lett. 113186102

14. Guo C-S, Xin X, Van Hove M A, Ren X and Zhao Y 2015 J. Phys. Chem. C 11914195

15. Buckingham A D, Del Bene J E and McDowell S A C 2008 Chem. Phys. Lett. $\mathbf{4 6 3} 1$

16. Parajuli R and Arunan E 2013 Chem. Phys. Lett. 568-569 63

17. Buckingham A D and Fowler P W 1985 Can. J. Chem. 632018

18. Politzer P, Lane P, Concha M C, Ma Y and Murray J S 2007 J. Mol. Model. 13305

19. Politzer P, Murray J S and Concha M C $2007 \mathrm{~J}$. Mol. Model. 13643

20. Desiraju G R and Steiner T 1999 In The Weak Hydrogen Bond: In Structural Chemistry in Biology (Oxford UK: Oxford University Press)

21. Jeffery G A and Saenger W 1991 In Hydrogen Bonding in Biological Structure (Berlin: Springer Verlag)

22. E Weber, Y Aoyama, M R Caira, G R Desiraju, J P Glusker, A D Hamilton, R E Meléndez and A Nangia (Eds.) 1998 In Design of Organic Solids, Topics in Current Chemistry Vol. 198 (Berlin Heidelberg: Springer) 
23. Raghavendra B, Mandal P K and Arunan E 2006 Phys. Chem. Chem. Phys. 85276

24. Lakshmi B, Samuelson A G, Jovan Jose K V, Gadre S R and Arunan E 2005 New J. Chem. 29371

25. Arunan E, Tiwari A P, Mandal P K and Mathias P C 2002 Curr. Sci. 82533

26. Gadre S and Bhadane P 1997 J. Chem. Phys. 1075625

27. Bader R F W 1990 In Atoms in Molecules: A Quantum Theory (Oxford UK: Oxford University Press)

28. Klein R A 2006 Chem. Phys. Lett. 425128

29. Klein R A 2002 J. Am. Chem. Soc. 12413931

30. Nyburg S C 1979 Acta Crystallogr. Sect. A 35641

31. Nyburg S C and Faerman C H 1985 Acta Crystallogr. Sect. B Struct. Sci. 41274

32. Eramian H, Tian Y-H, Fox Z, Beneberu $\mathrm{H} Z$ and Kertesz M 2013 J. Phys. Chem. A 11714184

33. Legon A and Millen D 1987 Chem. Soc. Rev. 16467

34. Gadre S R and Shirsat R N 2000 In Electrostatics of Atoms and Molecules (Hyderabad: Universities Press)

35. P Politzer and D G Truhlar (Eds.) 1981 In Chemical Applications of Atomic and Molecular Electrostatic Potentials (New York: Springer)

36. Suresh C H and Koga N 2002 J. Am. Chem. Soc. 124 1790

37. Kumar A, Gadre S R, Mohan N and Suresh C H 2014 J. Phys. Chem. A 118526

38. Frisch M J, Trucks G W, Schlegel H B, Scuseria G E, Robb M A, Cheeseman J R, Scalmani G, Barone V, Mennucci B, Petersson G A, Nakatsuji H, Caricato M, Li X, Hratchian H P, Izmaylov A F, Bloino J, Zheng G, Sonnenberg J L, Hada M, Ehara M, Toyota K, Fukuda R, Hasegawa J, Ishida M, Nakajima T, Honda Y, Kitao O,
Nakai H, Vreven T, Montgomery Jr. J A, Peralta J E, Ogliaro F, Bearpark M, Heyd J J, Brothers E, Kudin K N, Staroverov V N, Keith T, Kobayashi R, Normand J, Raghavachari K, Rendell A, Burant J C, Iyengar S S, Tomasi J, Cossi M, Rega N, Millam J M, Klene M J, Knox E, Cross J B, Bakken V, Adamo C, Jaramillo J, Gomperts R, Stratmann R E, Yazyev O, Austin A J, Cammi R, Pomelli C, Ochterski J W, Martin R L, Morokuma K, Zakrzewski V G, Voth G A, Salvador P, Dannenberg J J, Dapprich S, Daniels A D, Farkas O J, Foresman B, Ortiz J V, Cioslowski J and Fox D J 2013 In Gaussian 09, Revision D.01 (Wallingford CT: Gaussian, Inc.)

39. Todd A and Keith T K 2013 AIMAll (Version 13.11.04) (Gristmill Software: Overland Park KS, USA)

40. Bondi A 1964 J. Phys. Chem. 68441

41. Nyburg S C, Faerman C H and Prasad L 1987 Acta Crystallogr. Sect. B Struct. Sci. 43106

42. Chopra D, Row Guru T N, Arunan E and Klein R A 2010 J. Mol. Struct. 964126

43. Goswami M and Arunan E 2011 Phys. Chem. Chem. Phys. 1314153

44. Johnson E R, Keinan S, Mori-Sánchez P, ContrerasGarcía J, Cohen A J and Yang W 2010 J. Am. Chem. Soc. 1326498

45. Lane J R, Contreras-García J, Piquemal J-P, Miller B and Kjaergaard H J 2013 J. Chem. Theo. Comput. 93263

46. Lakshmipriya A, Rama Chaudhari S, Shahi A, Arunan E and Suryaprakash N 2015 Phys. Chem. Chem. Phys. 177528

47. Shahi A and Arunan E 2015 Phys. Chem. Chem. Phys. 1724774 